\title{
Lactate clearance at 6 hours after admission as a predictor of mortality in children with clinically suspected sepsis
}

\author{
Komal Zanak ${ }^{1}$, *Diganta Saikia ${ }^{1}$, Sikha Sharma $^{1}$, Arpita Chattopadhya ${ }^{1}$ \\ Sri Lanka Journal of Child health, 2022; 51(1): 34-38 \\ DOI: http://dx.doi.org/10.4038/sljch.v51i1.9996
}

\begin{abstract}
Background: Causes of death in children with severe sepsis include septic shock, end organ damage and multiple organ dysfunction syndrome (MODS).
\end{abstract}

Objective: To ascertain whether lactate clearance predicts outcome of children with sepsis

Method: Prospective observational study was carried out among 100 children aged between 1 month and 12 years with clinical features of clinically suspected sepsis (Proven or suspected infection fulfilling at least two of the four criteria of Systemic Inflammatory Response Syndrome (SIRS)). Relevant investigations were carried out.

Results: The mean age of the children was 2.55 years. The incidence of death among the lactate nonclearance group was $84.2 \%$, significantly more compared to $17.8 \%$ among survivors. About $91.6 \%$ of the area was under curve which was statistically significant with a cut off value of lactate clearance less than or equal to $12.7 \%$. The sensitivity at this level was $84.2 \%$, specificity was $91.3 \%$, positive likelihood ratio was 8.7, and negative likelihood ratio was 0.17 . Lactate at zero hours and six hours was significantly more among non-survivors compared to survivors.

Conclusions: The serum lactate clearance level at 6 hours of admission demonstrated that it is a sensitive and specific marker in prediction of the mortality.

(Key words: Lactate clearance, Admission, Predictor, Mortality, Children, Sepsis)

${ }^{1}$ Chacha Nehru Bal Chikitsalaya, Geeta Colony,
Delhi, India
${ }^{* C o r r e s p o n d e n c e: ~ d r d s k 14 @ g m a i l . c o m ~}$
iD $h$ https//orcid.org/0000-0002-2409-8108

(Received on 23 December 2020: Accepted after revision on 19 February 2021)

The authors declare that there are no conflicts of interest

Personal funding was used for the project.

Open Access Article published under the Creative

Commons Attribution CC-BY (c) (i) License

\section{Introduction}

Causes of death in children with severe sepsis include septic shock, end organ damage and multiple organ dysfunction syndrome (MODS) ${ }^{1}$. Resuscitation efforts are based on improvement in clinical parameters such as peripheral perfusion, capillary refill $<3$ seconds, heart rate appropriate for age and mental status, along with clearance in lactate $(<2 \mathrm{mmol} / \mathrm{L})$ and normalization of central venous oxygen saturation $(>70 \%)$ as per surviving sepsis guidelines ${ }^{2}$. In situations of sepsis, hypoperfusion leads to global tissue hypoxia, pyruvate no longer entering mitochondria for aerobic metabolism but being preferentially reduced to lactate, resulting in lactate accumulation in the blood ${ }^{3}$. It was noted that patients whose lactate levels decreased with therapy had better outcome than those with persistent elevated lactate levels ${ }^{3}$. Hence the lactate level was useful as a diagnostic, monitoring and prognostic biomarker. To date, no lactate clearance cutoff value has been agreed upon. A study used a cutoff point of $>10 \%$ within the first 6 hours of treatment, and reported that any increase in lactate clearance by $10 \%$ reduced mortality in adults with sepsis ${ }^{4}$. Increased serum lactate level is indicative of anaerobic metabolism caused by tissue hypoxia, and is a good marker to assess tissue perfusion in sepsis. A state of hyperlactataemia (serum lactate $>2$ $\mathrm{mmol} / \mathrm{L}$ ) is a cardinal sign of sepsis ${ }^{5}$. However, the majority of research with serum lactate and lactate clearance in sepsis has been conducted in adults and paediatric data is scarce.

\section{Objectives}

To ascertain whether lactate clearance predicts outcome of children with sepsis.

\section{Method}

A prospective observational study was carried out among 100 in-patients of the paediatric department, Chacha Nehru Bal Chikitsalaya, Delhi from January 2018 to December 2019.

Sample size: Assuming the mortality in lactate nonclearance group as $60 \%$ in patients with severe sepsis $^{6}$, sample size estimation was done based on sample size $(\mathrm{n})=\mathrm{Z}^{2} \mathrm{p}(1-\mathrm{p}) / \mathrm{d}^{2}$

$Z=Z$ value (e.g. 1.96 for $95 \%$ confidence level); $p$ $=$ prevalence $(06) ; \mathrm{d}=$ precision $(10 \%)$

$$
(1.96)^{2} \times 0.6 \times(1-0.6) /(0.1)^{2}=92
$$

Assuming attrition rate of $10 \%$, we planned to recruit 100 cases. 
Inclusion criteria: Children aged between 1 month and 12 years with features of clinically suspected sepsis (Proven or suspected infection fulfilling at least two of the four criteria of Systemic Inflammatory Response Syndrome (SIRS).

\section{Exclusion criteria:}

- Severe dehydration.

- Patients with diabetic ketoacidosis.

- Known case of chronic liver disease

- Known case of chronic kidney disease

All children with clinically suspected sepsis were enrolled in the study. Sepsis was suspected in those children with proven or suspected infection fulfilling two or more of the 4 SIRS criteria.

\section{SIRS criteria ${ }^{7}:$}

1. Abnormal temperature or leucocyte count [Leucocyte count elevated or depressed for age (not secondary to chemotherapyinduced leucopenia) or $10 \%$ immature neutrophils].

2. Core body temperature $>38.5^{\circ} \mathrm{C}$ or $<36^{\circ} \mathrm{C}$.

3. Tachycardia, defined as a mean heart rate $>2 \mathrm{SD}$ above normal for age in the absence of external stimulus, chronic drugs, or painful stimuli or otherwise unexplained persistent elevation over a 0.5 - 4-hour time period or for children $<1$ year old. Bradycardia was defined as a mean heart rate $<10^{\text {th }}$ percentile for age in the absence of external vagal stimulus, beta-blocker drugs, or congenital heart disease or otherwise unexplained persistent depression over a 0.5 -hour time period.

4. Mean respiratory rate $>2 \mathrm{SD}$ above normal for age or mechanical ventilation for an acute process not related to underlying neuromuscular disease or the receipt of general anesthesia.

Lactate clearance was calculated at 6 hours of admission and depending on lactate clearance children were divided into two groups as lactate non-clearance and lactate clearance.

- Lactate clearance=lactate decreased by $12.7 \%$ or greater from admission lactate level

- $\quad$ Lactate non-clearance $=$ lactate decreased by less than $12.7 \%$ from initial or nonreduction of lactate from admission lactate level.

Other tests performed: Complete blood count with differential count, renal function tests, liver function tests, serum lactate level (at admission and after 6 hours), blood culture, venous blood gas analysis (at 0 and 6 hours).
Sample was collected for above mentioned blood tests and necessary parameters were noted; 8-10 ml of venous blood was collected and distributed as per standard guidelines. Repeat serum lactate at 6 hours for lactate clearance calculation was done.

Other parameters noted: Glasgow coma scale, systolic and diastolic blood pressure.

Patients were followed till death or hospital discharge and final outcome was taken as survival or non-survival.

\section{Definitions:}

- Lactate clearance ${ }^{8}$. defined as the percentage change in lactate levels after six hours from a baseline measurement in the emergency department (ED).

- Sepsis $^{4}$ : defined as life-threatening organ dysfunction caused by a dysregulated host response to infection.

- Severe sepsis ${ }^{5}$ : defined as sepsis associated with organ dysfunction or tissue hypoperfusion.

- Fluid-refractory shock: No response to initial fluid resuscitation of up to $60 \mathrm{ml} / \mathrm{kg}$ of isotonic crystalloid/colloid bolus administered in a 15 minutes period.

- Reversal of shock: Attainment of normal pulses, capillary refill time (CRT), mean arterial pressure (MAP), central venous pressure (CVP), urine output and mental status. Normalization of metabolic parameters - lactate clearance, increase in central venous oxygen saturation $>70 \%$.

Ethical issues: Ethics clearance was granted by the Institutional Ethics Committee, Chacha Nehru Bal Chikitsalaya, Geeta Colony, Delhi, India (No. F1/IEC/CNBC/03/01/2019/2469). Written informed consent of parents was taken before enrolling children into study.

Data analysis: Categorical variables were presented in number and percentage and continuous variables were presented as mean \pm SD and median. Normality of data was tested by Kolmogorov-Smirnov test. If the normality was rejected, then a non-parametric test was used. Quantitative variables were compared using Independent t-test / Mann-Whitney test (when the data sets were not normally distributed) between the two groups. Qualitative variables were correlated using Chi-Square test. Receiver operating characteristic curve was used to find out cut-off point of lactate clearance for predicting mortality. A $\mathrm{p}$ value $<0.05$ was considered statistically significant. The data was entered in MS EXCEL spreadsheet and analysis was done using Statistical Package for Social Sciences (SPSS) version 21.0. 


\section{Results}

The mean age of the children was 2.55 years, the mean duration of hospitals stay was 6.9 days, mean lactate at 0 hour was 3.96 and at 6 hours was 3.32 mmol/L. The mean lactate clearance was $17.19+10.51 \%$ and the mean platelet count was 200,270/microlitre (Table 1). The incidence of death among the lactate non-clearance group was $84.2 \%$ compared to $9.6 \%$ among the lactate clearance group. This association was found to be statistically significant $(\mathrm{p}<0.05)$. The odds ratio of death was $49.78(95 \% \mathrm{CI}=14.81-167.3)$ among those children with lactate non-clearance $(\mathrm{p}<0.05)$ (Table 2$)$

Table 1

Distribution of study group according to age, duration of hospital stay, lactate levels and platelet count (n=100)

\begin{tabular}{|l|c|c|c|c|}
\hline \multicolumn{1}{|c|}{ Variable } & Mean \pm SD & Median & Min-max & Inter-quartile range \\
\hline Age (years) & $2.55 \pm 2.61$ & 1.6 & $0.12-11$ & $0.50-4$ \\
\hline Duration of hospital stay (days) & $6.9 \pm 3.67$ & 6 & $1-20$ & $4-9$ \\
\hline Blood lactate at zero hours (mmol/L) & $3.96 \pm 1.41$ & 3.6 & $2.1-8$ & $2.75-4.95$ \\
\hline Blood lactate at six hours (mmol/L) & $3.32 \pm 1.4$ & 2.85 & $1.6-8.9$ & $2.2-4.3$ \\
\hline Lactate clearance (\%) & $17.19 \pm 10.51$ & 16.6 & $-11.2-45.9$ & $10-25.5$ \\
\hline Platelet count / microlitre & $200,270 \pm 117,729$ & 178,000 & $40,000-640,000$ & $116,000-247,500$ \\
\hline
\end{tabular}

SD: standard deviation, Min-max: Minimum-maximum

Table 2: Mortality in lactate clearance and non-clearance groups

\begin{tabular}{|c|c|c|c|c|c|c|}
\hline Lactate clearance status & Non-survivors & Survivors & Chi square & p-value & Odds ratio & 95\% CI \\
\hline$\leq 12.7 \%$ (non-clearance) & $32(84.2 \%)$ & $06(17.8 \%)$ & \multirow{3}{*}{52.45} & \multirow{3}{*}{$<0.0001$} & \multirow{3}{*}{49.78} & \multirow{3}{*}{$14.81-167.3$} \\
\hline$>12.7 \%$ (clearance) & $06(09.6 \%)$ & $56(90.4 \%)$ & & & & \\
\hline Total & $38(38.0 \%)$ & $62(62.0 \%)$ & & & & \\
\hline
\end{tabular}

About $91.6 \%$ of the area was under curve which was statistically significant with a cut off value of lactate clearance less than or equal to $12.7 \%$. The sensitivity of lactate clearance at this level was
$84.2 \%$, specificity was $91.3 \%$, positive likelihood ratio was 8.7 , and negative likelihood ratio was 0.2 (Table 3).

Table 3: Area Under Curve (AUC), cut off value and predictive accuracy of lactate clearance as predictor of mortality in children with sepsis

\begin{tabular}{|c|c|c|c|c|c|}
\hline Parameter & AUC & Standard error & $\mathbf{9 5 \%}$ CI & P value & Cut off value \\
\hline Lactate clearance (\%) & 0.916 & 0.03 & $0.844-0.962$ & $<0.0001$ \\
\hline \multicolumn{7}{|c|}{ Parameter } & $\begin{array}{c}\text { Sensitivity } \\
(\mathbf{9 5 \%} \text { CI) }\end{array}$ & $\begin{array}{c}\text { Specificity } \\
\mathbf{( 9 5 \%} \text { CI) }\end{array}$ & $\begin{array}{c}\text { +likelihood } \\
\text { ratio (95\% CI) }\end{array}$ & $\begin{array}{c}\text { Negative likelihood } \\
\text { ratio (95\% CI) }\end{array}$ & $\begin{array}{c}\text { positive predictive } \\
\text { value (95\% CI) }\end{array}$ \\
\hline Lactate clearance (\%) & $84.21(68.7-94.0)$ & $90.32(80.1-96.4)$ & $8.7(4.0-18.8)$ & $0.17(0.08-0.4)$ & $84.2(68.7-94.0)$ \\
\hline
\end{tabular}

CI: confidence interval

Blood lactate at zero hours and six hours was significantly higher among non-survivors compared to survivors. Duration of hospital stay and albumin levels were significantly less among non-survivors compared to survivors.

\section{Discussion}

There were 100 patients who met the inclusion criteria. Overall death rate was 38\%. The mean age of the children was 2.55 years and the predominant age group was $1-5$ years; $54 \%$ were males. Aramburo A, et al $l^{9}$ observed similar findings. In a study by Nazir M, et $a l^{10}, 46 \%$ of the children were males. In our study the mean duration of hospital stay was 6.9 days; mean lactate at zero hour was 3.96 and at six hours was $3.32 \mathrm{mg} / \mathrm{dL}$. The mean lactate clearance was $17.19 \pm 10.51 \%$ and mean platelet count was 200,270/cu mm. In a study by Aramburo $\mathrm{A}$, et $a l^{9}$, the median age was 24 months among all children, the mean lactate at the time of admission was $3.8 \mathrm{mmol} / \mathrm{L}$. In a study by Nazir M, et $\mathrm{al}^{10}$, the median age was 22 months, the lactate at the time of admission was $6.1 \mathrm{mmol} / \mathrm{L}$; the percentage of lactate clearance was $57.9 \%$ within 6 hours.

In our study a lactate clearance cut off of $12.7 \%$ had maximum sensitivity plus specificity for predicting hospital mortality. After six hours intervention, a lactate clearance of $12.7 \%$ had a sensitivity of $84.2 \%$ and a specificity of $90.3 \%$. Patients were then categorized into the non-clearance group $(<12.7 \%$ clearance) and clearance group ( $>12.7 \%$ clearance). In a study by Saputra DK, et $a l^{11}$, the outcome between patients with lactate clearance of less than or equal to $34.7 \%$ and more than $34.7 \%$ was statistically significant. This difference may be due to the different cut-off points chosen in these two studies. In our study of 100 patients, 62 had lactate clearance and 38 had lactate non-clearance; mortality was $84.2 \%$ in the lactate non-clearance group versus $9.6 \%$ in the lactate clearance group ( $p$ $<0.001)$. 
In our study, mean ages of the children with lactate clearance $(>12.7 \%)$ vs non-clearance $(<12.7 \%)$ groups were 2.51 years and 2.62 years respectively which was not statistically significant. In a study by Nazir $\mathrm{M}$, et $a l^{10}$, the median age among the survivors was 22.8 months and 24.2 months among the non survivors. Among lactate clearance group 50\% were male and $50 \%$ were female and in non-lactate clearance group $34.2 \%$ were female and $65.8 \%$ were males. There was no statistical significance of gender in lactate clearance $(p=0.123)$. No studies compared these results.

There are some limitations to the study. This is a non-experimental observational study and as such can detect only the association between lactate clearance and mortality but cannot establish cause and effect. Performing serial lactate measurement in patients with sepsis is not a mandatory practice in our centres and measurements are performed at the discretion of the clinician, so this could potentially represent a source of selection bias

\section{Conclusions}

The serum lactate clearance level at 6 hours after admission is a sensitive and specific marker in prediction of mortality. A lactate clearance cut off of $12.7 \%$ had the maximum sensitivity plus specificity for predicting hospital mortality.

\section{References}

1. Pawar A, Raut A, Kalrao V, Jacob J, Godha I. Aetiology and clinical outcomes of neonatal and paediatric sepsis. Archives of Pediatric Infectious Diseases 2016; 4(2): e33602. https://doi.org/10.5812/pedinfect.33602

2. Levy MM, Evans LE, Rhodes A. The surviving sepsis campaign bundle: 2018 update. Intensive Care Medicine 2018; 44: 925-8.

https://doi.org/10.1007/s00134-018-50850

PMid: 29675566

3. Zhang Z, Xu X, Chen K. Lactate clearance as a useful biomarker for the prediction of all-cause mortality in critically ill patients: a systematic review study protocol. $B M J$ Open 2014; 4: e004752. https://doi.org/10.1136/bmjopen-2013004752

PMid: 24860001 PMCid: PMC4039865

4. Nguyen HB, Rivers EP, Knoblich BP, Jacobsen G, Muzzin A, Ressler JA, et al. Early lactate clearance is associated with improved outcome in severe sepsis and septic shock. Critical Care Medicine 2004; 32: $1637-42$.

https://doi.org/10.1097/01.CCM.00001329

04.35713.A7

PMid: 15286537

5. Jat KR, Jhamb U, Gupta VK. Serum lactate levels as the predictor of outcome in paediatric septic shock. Indian Journal of Critical Care Medicine 2011; 15: 102-7. https://doi.org/10.4103/0972-5229.83017 PMid: 21814374 PMCid: PMC3145293

6. Jones AE, Shapiro NI, Trzeciak S. Lactate clearance vs central venous oxygen saturation as goals of early sepsis therapy: a randomized clinical trial. Journal of the American Medical Association 2010; 303(8): 739-46.

https://doi.org/10.1001/jama.2010.158

PMid: 20179283 PMCid: PMC2918907

7. Goldstein B, Giroir B, Randolph A. International Consensus Conference on Paediatric Sepsis International pediatric sepsis consensus conference: definitions for sepsis and organ dysfunction in paediatrics. Pediatric Critical Care Medicine 2005; 6: 2-8.

https://doi.org/10.1097/01.PCC.00001491 31.72248.E6

PMid: 15636651

8. Bai Z, Zhu X, Li M. Effectiveness of predicting in-hospital mortality in critically ill children by assessing blood lactate levels at admission. BMC Pediatrics 2014; 14: 83.

https://doi.org/10.1186/1471-2431-14-83

PMid: 24673817 PMCid: PMC3976355

9. Aramburo A, Todd J, George EC. Lactate clearance as a prognostic marker of mortality in severely ill febrile children in East Africa. BMC Medicine 2018; 16: 37. https://doi.org/10.1186/s12916-018-1014$\mathrm{x}$

PMid: 29519240 PMCid: PMC5844084

10. Nazir M, Wani W, Dar SA, Mir HQ, Charoo BA, Ahmad QI, et al. Lactate clearance prognosticates outcome in paediatric septic shock during first 24 hours of intensive care unit admission. Journal of the Intensive Care Society 2019; 20(4): 290-8. https://doi.org/10.1177/175114371985520 2

PMid: 31695733 PMCid: PMC6820231 
11. Saputra DK, Tatura SN, Runtunuwu AL, Manoppo JI. Lactate clearance and mortality in paediatric sepsis. Paediatrica Indonesiana 2016; 56(4): 215.

https://doi.org/10.14238/pi56.4.2016.21520

12. Munde A, Kumar N, Beri BS, Puliyel JM. Lactate clearance as a marker of mortality in Paediatric Intensive Care Unit. Indian Pediatrics 2014; 51: 565-7.

https://doi.org/10.1007/s13312-014-04482

PMid: 25031136
13. Kim YA, Ha EJ, Jhang WK, Park SJ. Early blood lactate area as a prognostic marker in paediatric septic shock. Intensive Care Medicine 2013; 39: 1818-23. https://doi.org/10.1007/s00134-013-2959$\mathrm{Z}$

PMid: 23818093 